\title{
Genetic Basis of Gynaecological Cancers
}

\author{
Mala Srivastava $^{1^{*}}$, Neha Ahlawat ${ }^{2}$, Ankita Srivastava ${ }^{3}$ \\ ${ }^{1}$ Institute of Obstetrics and Gynaecology, Sir Ganga Ram Hospital, New Delhi, India \\ ${ }^{2}$ Sir Ganga Ram Hospital, New Delhi, India \\ ${ }^{3}$ Lok Nayak Jai Prakash Narayan Hospital, New Delhi, India
}

*Corresponding author: Mala Srivastava, Senior Consultant \& Robotic Surgeon, Institute of Obstetrics and gynaecology, Sir Ganga Ram Hospital, New Delhi, India. Tel: +919811228336; E-mail: malasrivastava2001@yahoo.co.in

Citation: Srivastava M, Ahlawat N, Srivastava A (2017) Genetic Basis of Gynaecological Cancers. Gynecol Obstet Open Acc: OBOA-103. DOI: 10.29011/ OBOA-103. 100003

Received Date: 20 March, 2017; Accepted Date: 28 July, 2017; Published Date: 7 August, 2017

\begin{abstract}
There has been an enormous progress in understanding of the molecular basis of disease, process of carcinogenesis \& their impact on gynaecological cancers. This fundamental understanding is achieved; using molecular technology which provides opportunities for the prevention, early detection and adequate management of cancer. It is understood that cancer patients with same histological tumour variety and stage may have a different clinical outcome. Because there is biological diversity of tumours, which cannot be explained by microscopic type alone. So, the current focus of describing tumours is the analysis of gene expression using new DNA microarray technology.

Gynaecological cancers are examples of a number of contrasting mechanisms of carcinogenesis. It is known that, ovarian and endometrial cancer can occur as components of familial cancer syndromes (familial breast/ovarian cancer and Lynch II syndrome) due to germline inheritance of genetic abnormalities. However, most ovarian cancers are not considered to be due to inherited genetic alterations, but occur due to somatic mutations occurring in ovarian cells with an initially normal genome. These somatic mutations are considered to be secondary to environmental factors that increase the opportunity for spontaneous mutation in a number of susceptible genes. For example the genetic alterations that lead to cervical cancer is caused by an environmental factor, Human Papilloma Virus (HPV), and in some endometrial cancers, unopposed oestrogen exposure or hyperinsulinism that leads to carcinogenesis. This proposes that vulval and cervical carcinomas are not similar aetiologically, and that factors other than HPV infection are more important in vulval carcinogenesis. Various genetic events occur between HPV-positive and -negative vulval cancers, with a larger number of molecular alterations in HPV-negative vulval cancers compared with HPV-positive tumours [1].

As a result, HPV-positive vulval cancers are more frequently found in younger patients. Whereas, vulval cancers in older patients are more often HPV negative, and more often show allelic loss of the TP53 gene. Approximately 5\% of endometrial cancers and $10 \%$ of ovarian cancers are attributed to an inherited predisposition [2,3]. Given the current incidence of these diseases in the United States, hereditary cancer syndromes will lead to approximately 2200 new cases of ovarian cancer and 2300 new cases of endometrial cancer in 2011 [4].
\end{abstract}




\section{HBOC Syndrome}

HBOC syndrome is caused by mutations in the BRCA1 or BRCA2 genes. These genes were initially identified and cloned in the early 1990s [5,6]. The prevalence of mutations in BRCA1 and BRCA2 among the general population has been estimated to be 1 in 400 [7].

BRCA mutation carriers are also at risk of many other cancers. The other rare cancers reported to be associated with BRCA mutations are male breast, pancreatic, melanoma Biliary cancer and prostate cancers, although lifetime risk of these cancers is low compared with female breast and ovarian cancer. The melanoma and biliary cancers, have also been reported to occur in BRCA carriers [8-12].

It is being noted that $5 \%$ of endometrial carcinomas and $20 \%$ of epithelial ovarian cancers are hereditary [13-15]. These are autosomal dominant disorders, Hereditary Breast and Ovarian Cancer (HBOC) and Lynch syndrome (formerly referred to as Hereditary Nonpolyposis Colorectal Carcinoma, HNPCC) causes the majority of this inherited susceptibility [16]. The other rare syndromes such as Cowden, Peutz-Jeghers and Li-Fraumeni can also manifest with gynaecological malignancies. Besides, recent Genome-Wide Association Studies (GWAS) have highlighted the role of lower-penetrance variants in gynaecological cancer. It is important to identify those at increased risk in order to ensure that optimal preventive and treatment strategies are offered to women and their families [17].

\section{Hereditary Breast and Ovarian Cancer}

The BRCA1 and BRCA2 genes were first identified and cloned in the early 1990s $[18,19]$. Women with a BRCA1 mutation have a lifetime risk of ovarian cancer of $63 \%$ and of breast cancer of up to $85 \%$. Lifetime risks of ovarian and breast cancers in women among BRCA2 carriers are reported to be up to $27 \%$ and $84 \%$ respectively $[20,21]$.

\section{Lynch Syndrome}

The Lynch syndrome is caused by mutations in the DNA Mismatch Repair (MMR) genes (MSH2, MLH1, MSH6, and PMS2) [22-25]. This condition causes an increased risk of earlyonset cancer of multiple types, including colorectal, endometrial, ovarian, gastric, small bowel, hepatobiliary, and brain, ureteric and renal pelvic cancers [26]. The lifetime risk for endometrial cancer is $40-60 \%$ whereas there is a risk of $3 \%$ in the general population. However, this risk may exceed the risk of colorectal cancer for women with Lynch syndrome, especially those that carry an MSH6 mutation [27]. Whereas, for ovarian carcinoma, the risk is $10-12 \%$ compared with the general population risk of $1.4 \%$ [28].

\section{Cowden syndrome}

Cowden syndrome is caused by germline mutations in the tumour suppressor gene PTEN and causes PTEN Hamartoma Tumour Syndrome (PHTS), encompasses the autosomal dominant conditions Cowden Syndrome (CS), in adulthood, and Bannayan-RileyRuvalcaba syndrome in children. CS is a cancer predisposition syndrome characterised by macrocephaly, multiple hamartomas and an increased risk of breast, thyroid and endometrial cancers, as well as colorectal, melanoma and renal cell carcinoma [29]. Though the penetrance of this condition is high, there is significant variability in its manifestation among families.

\section{Peutz-Jeghers syndrome}

Peutz-Jeghers syndrome is caused by germline mutations in the STK11 gene. It is an autosomal dominant gastrointestinal polyposis disorder with an increased risk of breast, gastrointestinal and gynaecological tumours. The women have high characteristic pigmented lesions on the lips and buccal mucosa. Women with PJS have risk of developing sex cord stromal tumours with annular tubules of the ovary and adenoma malignum of the cervix.

\section{Li-Fraumeni syndrome}

Li-Fraumeni Syndrome (LFS) is caused by germline TP53 mutations. The important features of this condition are young-onset sarcomas, breast cancer, adrenocortical carcinoma and childhood tumours [30]. Gynaecological malignancies are not common. Though the most commonly diagnosed condition is epithelial ovarian carcinoma.

\section{Management of Familial Gynaecological Can- cer}

\section{Risk assessment}

At present, risk assessment is based largely upon information derived from a detailed family history tree. Important information includes the number of cases of cancer relative to the number of people at risk, the pattern of cancers of different types, and the age at diagnosis of cancer.

It is difficult to define the minimum family history necessary to satisfy the description of a familial cancer syndrome involving a gynaecological cancer.

- Families in which two first-degree relatives have proven ovarian cancer;

- Families in which first-degree relatives have breast cancer at less than 50 years of age and ovarian cancer; and

- Families in which two first-degree relatives have breast cancer at less than 60 years of age and a third relative has ovarian cancer.

The high frequency of cancer in such families is due to an inherited predisposition rather than a chance event and the likelihood is in excess of $60 \%$. Families in which at least one relative 
has ovarian or endometrial cancer and two or more first-degree relatives have cancer of the colon/rectum with at least one relative having cancer at less than 50 years of age, can be classified as HNPCC families.

\section{Prevention of familial cancer}

Use of the oral contraceptive pill may be suggested for HNPCC and breast/ovarian cancer family members which indicate a protective effect against ovarian \& endometrial cancer. Furthermore, there is concern in breast/ovarian cancer families that a reduction in risk of ovarian cancer may be offset by an increased risk of breast cancer.

Prophylactic salpingo-oophorectomy and hysterectomy as a primary procedure is justifiable in women from breast/ovarian cancer and HNPCC families after completion of their family and after thorough counselling. There is convincing evidence that salpingo-oophorectomy is an effective method of prevention of cancer of the ovary, fallopian tube and breast. Women undergoing prophylactic surgery should be counselled that the procedure will prevent ovarian and tubal cancer, but that they may still be at risk of primary peritoneal cancer for which complete peritonectomy is required.

\section{Summary}

Although the majority of gynaecological cancers are sporadic, it is important that those cancers caused by an inherited predisposition are identified. Clinicians should be alert to the possibility of a hereditary condition when managing women with gynaecological cancer.

This ensures that patients and family members have information about chemoprevention, surveillance, risk-reducing surgery and psychological support and are referred appropriately. Notably, this involves a multidisciplinary team that enables women to have tailored management based on their individual medical history and preferences.

\section{References}

1. Flowers LC, Wistuba II, Scurry J, Muller CY, Ashfaq R, et al. (1999) Genetic changes during the multistage pathogenesis of humanpapillomavirus positive and negative vulvar carcinomas. J Soc Gynecol Investig 6: 213-221.

2. Gruber SB, Thompson WD (1996) A population-based study of endometrial cancer and familial risk in younger women. Cancer and hormone study group. Cancer Epidemiol Biomarkers Prev 5: 411-417.

3. Lancaster, JM (2008) Clinical relevance of hereditary ovarian cancer. In: Lu, KH., editor. Hereditary gynecologic cancer: risk, prevention, and management. Informa Healthcare; New York p. 1-13.

4. Siegel R, Ward E, Brawley O, Jemal A (2011) Cancer statistics, The impact of eliminating socioeconomic and racial disparities on premature cancer deaths. CA Cancer J Clin 61: 212-236.
5. Miki Y, Swensen J, Shattuck-Eidens D, Futreal PA, Harshman K, et al. (1994) A strong candidate for the breast and ovarian cancer susceptibility gene BRCA1. Science 266: 66-71.

6. Wooster R, Bignell G, Lancaster J, Swift S, Seal S, et al. (1995) Identification of the breast cancer susceptibility gene BRCA2. Nature 378: 789-792.

7. (2000) Prevalence and penetrance of BRCA1 and BRCA2 mutations in a population-based series of breast cancer cases. Anglian Breast Cancer Study Group. Br J Cancer 83: 1301-1308.

8. Petrucelli, N Daly, MB Feldman, GL (2011) BRCA1 and BRCA2 hereditary breast and ovarian cancer. In: Pagon RA, Bird TD, Dolan CR (editors) Gene Reviews. University of Washington; Seattle Pg no:1993-1998

9. Tai YC, Domcheck S, Parmigiani G, Chen S (2007) Breast cancer risk among male BRCA1 and BRCA2 mutation carriers. J Natl Cancer Inst 99: 1811-1814.

10. (1999) The Breast Cancer Linkage Consortium. Cancer risks in BRCA2 mutation carriers. J Natl Cancer Inst 91: 1310-1316.

11. Thompson D, Easton DF, T.B.C.L (2002) Consortium. Cancer incidence in BRCA1 mutation carriers. J Natl Cancer Inst 94: 1358-1365.

12. Risch HA, McLaughlin JR, Cole DEC, Rosen B, Bradley L, et al. (2006) Population BRCA1 and BRCA2 mutation frequencies and cancer penetrances: A kin-cohort study in Ontario. Canada. J Natl Cancer Inst 98: 1694-1706.

13. Gruber SB, Thompson WD (1996) A population-based study of endometrial cancer and familial risk in younger women. Cancer and Steroid Hormone Study Group. Cancer Epidemiol Biomarkers Prev 5: 411417.

14. Weissman SM, Weiss SM, Newlin AC (2012) Genetic testing by cancer site: ovary. Cancer J 18: 320-327.

15. Walsh T, Casadei S, Lee MK, Pennil CC, Nord AS, et al. (2011) Mutations in 12 genes for inherited ovarian, fallopian tube, and peritoneal carcinoma identified by massively parallel sequencing. Proc Natl Acad Sci USA 108: 18032-18037.

16. Bewtra C, Watson P, Conway T, Read-Hippee C, Lynch HT (1992) Hereditary ovarian cancer: a clinicopathological study. Int J Gynecol Pathol 11: 180-187.

17. Gayther SA, Pharoah PD (2010) the inherited genetics of ovarian and endometrial cancer. Curr Opin Genet Dev 20: 231-238.

18. Miki Y, Swensen J, Shattuck-Eidens D, Futreal PA, Harshman K, et al. (1994) A strong candidate for the breast and ovarian cancer susceptibility gene BRCA1. Science 266: 66-71.

19. Wooster R, Bignell G, Lancaster J, Swift S, Seal S, et al. (1996) Identification of the breast cancer susceptibility gene BRCA2. Nature 379: 749.

20. Easton DF, Ford D, Bishop DT (1995) Breast and ovarian cancer incidence in BRCA1-mutation carriers. Breast Cancer Linkage Consortium. Am J Hum Genet 56: 265-271.

21. Ford D, Easton DF, Stratton M, Narod S, Goldgar D, et al. (1998) Genetic heterogeneity and penetrance analysis of the BRCA1 and BRCA2 genes in breast cancer families. Am J Hum Genet 62: 676-689. 
Citation: Srivastava M, Ahlawat N, Srivastava A (2017) Genetic Basis of Gynaecological Cancers Gynecol Obstet Open Acc: OBOA-103.

22. Leach FS, Nicolaides NC, Papadopoulos N, Liu B, Jen J, et al. (1993) Mutations of a mutS homolog in hereditary nonpolyposis colorectal cancer. Cell 75: 1215-1225.

23. Fishel R, Lescoe MK, Rao MR, Copeland NG, Jenkins NA, et al. (1993) The human mutator gene homolog MSH2 and its association with hereditary nonpolyposis colon cancer. Cell 75: 1027-1038.

24. Papadopoulos N, Nicolaides NC, Wei YF, Ruben SM, Carter KC, et al. (1994) Mutation of a mutL homolog in hereditary colon cancer. Science 263: 1625-1629.

25. Kolodner RD, Tytell JD, Schmeits JL, Kane MF, Gupta RD, et al. (1999) Germ-line msh6 mutations in colorectal cancer families. Cancer Res 59: $5068-5074$

26. Lynch HT, de la Chapelle A (2003) Hereditary colorectal cancer. N Engl J Med 348: 919-932.
27. Hendriks YM, Wagner a, Morreau H, Menko F, Stormorken A, et al. (2004) Cancer risk in hereditary nonpolyposis colorectal cancer due to MSH6 mutations: impact on counseling and surveillance. Gastroenterology 127: 17-25.

28. Aarnio M, Sankila R, Pukkala E, Salovaara R, Aaltonen LA, de la Chapelle A, et al. (1999) Cancer risk in mutation carriers of DNA-mismatch-repair genes. Int J Cancer 81: 214-218.

29. Tan MH, Mester JL, Ngeow J, Rybicki LA, Orloff MS, et al. (2012) Eng C. Lifetime cancer risks in individuals with germline PTEN mutations. Clin Cancer Res 18: 400-407.

30. Li FP, Fraumeni JF, Mulvihill JJ, Blattner WA, Dreyfus MG, et al. (1988) A cancer family syndrome in twenty-four kindreds. Cancer Res 48 : $5358-5362$ 